Title

\title{
Effect of silicon content on densification, mechanical and thermal properties of Al-xSi binary alloys fabricated using selective laser melting
}

\section{Authors}

Takahiro Kimura $^{\mathrm{a}, \mathrm{b}, *}$, Takayuki Nakamoto ${ }^{\mathrm{a}}$, Masataka Mizuno ${ }^{\mathrm{b}}$, Hideki Araki ${ }^{\mathrm{b}}$

\begin{abstract}
Affiliations and addresses
${ }^{a}$ Technology Research Institute of Osaka Prefecture, 2-7-1 Ayumino, Izumi-shi, Osaka

594-1157, Japan

${ }^{\mathrm{b}}$ Division of Materials and Manufacturing Science, Osaka University, 2-1 Yamadaoka,
\end{abstract}

Suita-shi, Osaka 565-0871, Japan

* Corresponding author:

Takahiro Kimura

Tel: (81)725512673

Fax: (81)725512599 
e-mail: kimurata@tri-osaka.jp

\section{Abstract}

The effect of the silicon content on the densification of Al-xSi binary alloys $(\mathrm{x}=0$,

1, 4, 7, 10, 12, and 20 mass\%) fabricated using selective laser melting (SLM) were systematically studied. By optimizing laser scanning parameters for each Al-xSi powder, almost fully dense SLM samples (more than 99.5\% relative density) could be achieved for the Al-0Si (pure aluminum), and Al-4 20Si alloys. The Al-1Si SLM sample, on the other hand, contained many microcracks, considered to be solidification cracks. The Al-1Si SLM sample, in the solid-liquid coexisting state, was brittle and no healing of the cracks by the infiltration of the liquid phase occurred. Therefore, the cracks were easily generated due to thermally induced tensile stresses during solidification. The microstructures and the mechanical and thermal properties of the Al-xSi SLM samples fabricated using the optimal laser scanning parameters were examined. As the silicon content increased, the ultimate tensile strength and proof stress increased, whereas the elongation and thermal conductivity decreased. These mechanical properties were attributed to larger amounts of the crystalized phases of silicon (obstacles for the movement of dislocations) with increasing silicon content. The crystalized phases can also scatter conduction electrons, thereby decreasing the thermal conductivity. 
Keywords additive manufacturing; aluminum alloy; densification; microstructure; mechanical property; thermal conductivity

\section{Main text}

\section{Introduction}

Selective laser melting (SLM) is a well-known metal additive manufacturing $(\mathrm{AM}) / 3 \mathrm{D}$ printing process for producing $3 \mathrm{D}$ objects from metal powders by melting them with laser irradiation and stacking layer by layer. Gibson et al. [1] and Steen et al. [2] have explained the basic mechanisms of the AM and SLM processes. Recently, SLM has gained attention as a production technique for a wide variety of small quantity products as well as a prototyping. SLM can produce novel functional parts by producing complicated structures utilizing its layer-by-layer technological feature. Moreover, SLM materials typically have extremely fine microstructures with excellent mechanical properties, as the cooling rate of the SLM process is extremely high (about $1 \times 10^{6} \mathrm{~K} / \mathrm{s}$, as estimated by Steen et al. [3]). Nakamoto et al. [4] demonstrated that the proof stress and micro-hardness of SLM samples prepared from carbon steel powders were extremely higher than those of wrought steels because of the fine microstructures 
produced by the rapid cooling of SLM.

SLM with aluminum powders is expected to provide a suitable technology for manufacturing lightweight components and thermal control parts (ex. heat exchangers) in the aerospace, industrial machinery, and atomotive areas by taking advantage of the low density and/or high thermal conductivity of aluminum. Recently, many studies on aluminum SLM materials have been conducted. Kempen et al. [5] have produced ISO-A1Si10Mg alloy SLM samples with 98 99\% relative density and mechanical properties (ultimate tensile strength $\approx 390 \mathrm{MPa}$, breaking elongation of $3 \sim 5 \%$ ) equivalent to those of the casting sample. Kimura et al. [6] have shown that ISO-AlSi7Mg0.3 alloy SLM samples had sub-micron ordered fine cellular microstructures, and both the strength and elongation were greatly higher than those of AlSi7Mg0.3 casting material. Prashanth et al. [7] investigated the effect of heat treatment (annealing) on the microstructures and mechanical properties of ISO-AlSi12 SLM samples and found that the microstructures, and therefore the mechanical properties, changed considerably depending on the annealing temperature. Olakanmi [8] studied the selective laser sintering (SLS) of pure aluminum, Al-6Mg and Al-12Si alloy fabricated using an SLS machine equipped with a $\mathrm{CO}_{2}$ laser. He presented a process map for these aluminum SLS samples and discussed the consolidation mechanism 
needed to obtain high density samples. However, the relative density values of these SLS samples remained less than $75 \%$.

It is well known that silicon, one of the main solute elements in aluminum casting alloys, can strongly affect both the castability and mechanical properties. Kitaoka [9] reviewed the castability of Al-Si binary casting alloys, concluding that solidification cracks, flowability of molten metals, and shrinkage cavities varied drastically depending on the silicon content. Additionally, Kitaoka et al. [10] showed that the tensile strength and breaking elongation of Al-Si binary alloys remarkably increased and decreased, respectively, with increasing silicon content. Based on this knowledge, the silicon content in Al-Si SLM materials is also expected to affect the densification behavior during SLM and the properties of the materials. However, systematic studies on Al-Si binary SLM materials in relation to their silicon content have been rarely reported.

In this research, the effect of silicon content on the densification of Al-xSi binary alloys ( $\mathrm{x}=0,1,4,7,10,12$, and 20 mass $\%)$ fabricated using selective laser melting, was systematically studied. The optimal laser scanning parameters to densify the Al-xSi SLM samples were examined. Then, the microstructures and the mechanical and thermal properties of the SLM samples fabricated using the optimal laser scanning parameters were analyzed. Considering these results, we discuss the densification 
mechanism and relationship between the microstructures and properties of the $\mathrm{Al}-\mathrm{xSi}$

SLM samples.

\section{Experimental method}

\subsection{Materials and equipment}

The SLM samples used in this study were fabricated from Al-xSi $(\mathrm{x}=0,1,4,7$, 10, 12, and 20 mass\%) aluminum powders provided by Toyo Aluminium K.K. Japan. These powders consisted of either a solid solution $(\mathrm{x}=0,1)$, hypo-eutectic $(\mathrm{x}=4 \sim 10)$, near-eutectic $(\mathrm{x}=12)$, or hyper-eutectic $(\mathrm{x}=20)$ compositions in the Al-Si alloy system, as shown in Fig. 1. Table 1 shows the average particle diameter and chemical composition of the Al-xSi powders. All the powders had almost the same average particle diameter. The aluminum and silicon contents of the powders almost corresponded to the target compositions ( $\mathrm{x}$ mass $\%$ of $\mathrm{Al}-\mathrm{xSi}$ alloys), and the concentration of the other elements was identical for all Al-xSi alloys. Fig. 2 shows an

SEM image of Al-10Si powder. The powder particles were almost spherical; the other Al-xSi powders also showed similar morphologies. 


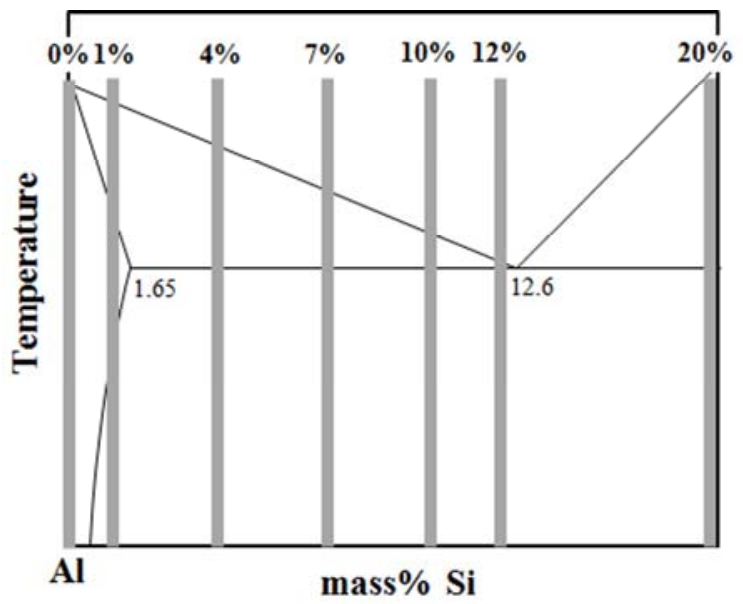

Fig. 1 Chemical composition of $\mathrm{Al}-\mathrm{xSi}$ powders shown on a schematic phase diagram of the Al-Si system alloy.

Table 1 Average particle diameter and chemical composition (mass\%) of Al-xSi powders.

\begin{tabular}{|c|c|c|c|c|c|c|c|c|c|c|}
\hline \multirow[t]{2}{*}{ Powder } & \multirow{2}{*}{$\begin{array}{c}\text { Sample } \\
\text { No. }\end{array}$} & \multirow{2}{*}{$\begin{array}{l}\text { Average particle } \\
\text { dlameter ( } \mu \text { in) }\end{array}$} & \multicolumn{8}{|c|}{ Chemical composition (mass\%) } \\
\hline & & & $\mathbf{C u}$ & $\mathbf{F e}$ & Si & Mn & $\mathrm{Mg}$ & $\mathbf{Z n}$ & Ii & AI \\
\hline Pure aluminum & Al-0SI & 22.5 & $<0.01$ & 0.12 & 0.05 & $<0.01$ & $<0.01$ & $<0.01$ & $<0.01$ & Bal. \\
\hline AI - 1 mass\%SI & Al-1Si & 22.5 & $<0.01$ & 0.14 & 1.02 & $<0.01$ & 0.01 & 0.01 & $<0.01$ & Bal. \\
\hline AI - 4 mass $\%$ SI & Al-4Si & 22.1 & $<0.01$ & 0.12 & 4.07 & $<0.01$ & $<0.01$ & 0.01 & $<0.01$ & Bal. \\
\hline AI - 7 mass\%SI & Al-7Si & 21.5 & $<0.01$ & 0.12 & 7.13 & $<0.01$ & $<0.01$ & 0.01 & 0.01 & Bal. \\
\hline AI - 10 mass $\%$ Si & Al-10Si & 21.4 & $<0.01$ & 0.11 & 10.38 & $<0.01$ & $<0.01$ & 0.01 & 0.01 & Bal. \\
\hline AI - 12 mass $\%$ Si & Al-12Si & 22.8 & $<0.01$ & 0.11 & 12.47 & $<0.01$ & 0.01 & $<0.01$ & 0.01 & Bal. \\
\hline AI- 20 mass $\%$ SI & Al-20SI & 22.2 & $<0.01$ & 0.10 & 20.07 & $<0.01$ & 0.01 & $<0.01$ & 0.01 & Bal. \\
\hline
\end{tabular}

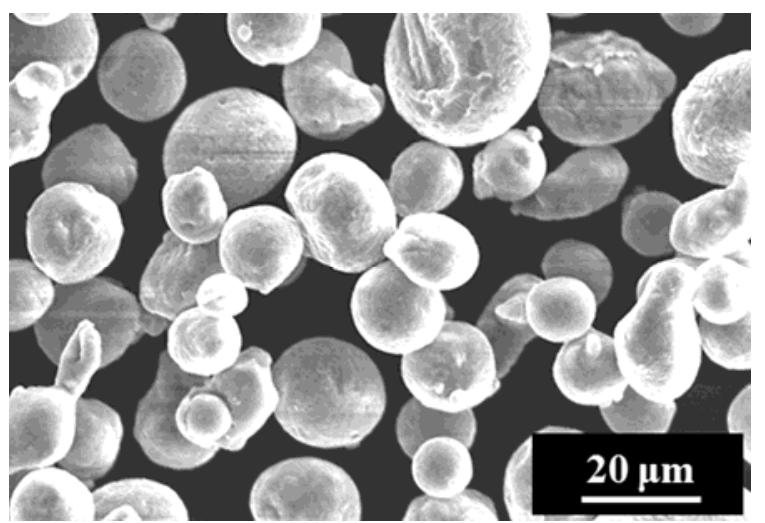

Fig. 2 SEM image of Al-10Si powder, representing the morphology of all test powders. 
Samples for testing were prepared using an SLM machine (EOSINT M280, EOS

$\mathrm{GmbH}$ ) having an Ytterbium fiber laser of $400 \mathrm{~W}$ class (beam diameter: approximately $0.1 \mathrm{~mm}$ ). Base plates (A5083) were preheated at $35^{\circ} \mathrm{C}$ in advance. The scanning pattern of the laser was rotated by $67^{\circ}$ with each new layer, with all samples being produced under an Ar atmosphere (oxygen concentration: around 0.1\%).

\subsection{Optimization of laser scanning parameters}

Optimal laser scanning parameters of each Al-xSi powder for densification were studied using columnar-shaped samples (diameter: $8 \mathrm{~mm}$, height: $15 \mathrm{~mm}$ ) fabricated by changing the laser power, scanning velocity, and scan distance (interval between the laser scanning lines) within the ranges shown in Table 2. The layer thickness was fixed at $0.03 \mathrm{~mm}$.

Table 2 Range of laser scanning parameters.

\begin{tabular}{lc}
\hline Layer thickness (mm) & 0.03 \\
Laser power (W) & $200-370$ \\
Scanning velocily $(\mathrm{mm} / \mathrm{s})$ & $400-3400$ \\
Scan distance $(\mathrm{mm})$ & $0.08-0.16$ \\
\hline
\end{tabular}

The densities of the SLM samples were measured using the Archimedes method. 
Optimal laser scanning parameters were selected as those for which the highest density could be obtained. The relative density values for the SLM samples fabricated using the optimal laser scanning parameters were derived through thresholding analysis (ImageJ, open source software for image analysis, National Institutes of Health) of five optical microscopic images taken from perpendicular sectional planes (XY-plane) to the stacking direction (Fig. 3).

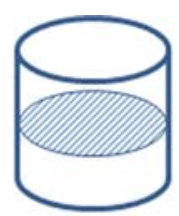

XY-plane

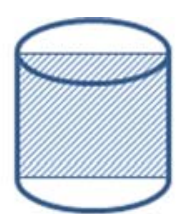

Z-plane
Stacking

direction

Fig. 3 Sectional planes of SLM samples for microstructural observation.

\subsection{Characterization of microstructures and properties}

Parallel (Z-plane) and perpendicular (XY-plane) sectional planes to the stacking direction of the SLM samples (Fig. 3) were mirror-finished by polishing and etched using Keller's reagent. The microstructures were then observed using optical microscopy (OM; MA100L, Nikon), field emission scanning electron microscopy (FE-SEM; JSM-6301F, JEOL), and an electron backscatter diffraction system (EBSD; OIM7.1, TSL) incorporated in the FE-SEM instrument (ERA-8900FE, ELIONIX). 
Tensile testing was used to evaluate the mechanical properties of the SLM samples using a materials testing machine (M4206, INSTRON) with a strain rate of $8.33 \times 10^{-2} / \mathrm{s}$. Columnar objects (diameter: $6 \mathrm{~mm}$, length: $38 \mathrm{~mm}$ ) for testing were fabricated using the optimal laser scanning parameters in directions both parallel $\left(0^{\circ}\right)$ and vertical $\left(90^{\circ}\right)$ to the stacking direction, as shown in Fig. 4, and then machined to dumbbell shapes as tensile samples (diameter: $3.5 \mathrm{~mm}$, length: $18 \mathrm{~mm}$, at the parallel part). The $0.2 \%$ proof stress was derived from the nominal stress-strain curve measured using an extensometer of camera system (iMETRUM Video Gauge 4 Lite, Imetrum). The fractured surfaces of the tensile samples were observed by scanning electron microscopy (SEM; S-3400N, Hitachi High-Technologies).

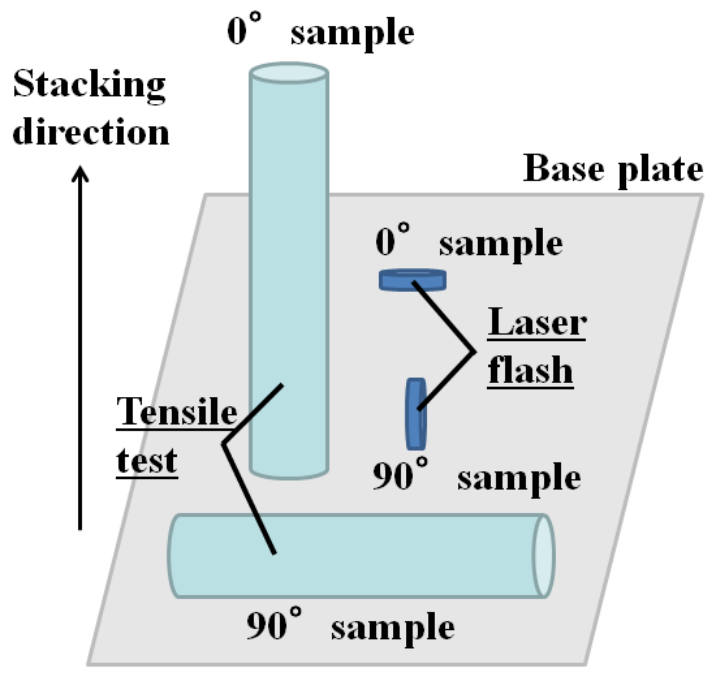

Fig. 4 Directions of SLM samples for tensile tests and laser flash measurements at angles of $0^{\circ}$ and $90^{\circ}$ to the stacking direction. 
The thermal property were evaluated from the thermal conductivity determined by the laser flash method, using a thermo-physical property analysis device (TC-7000H/SB-2, ULVAC RIKO). Disk objects (diameter: $10 \mathrm{~mm}$, thickness: $3.5 \mathrm{~mm}$ ) were fabricated using the optimal laser scanning parameters in directions both parallel $\left(0^{\circ}\right)$ and vertical $\left(90^{\circ}\right)$ to the stacking direction, as shown in Fig. 4. Both surfaces of these disks were polished to a thickness of approximately $3.0 \mathrm{~mm}$.

A single line bead with the Al-1Si powder was studied to investigate its basic characteristics. The powder was supplied on a base plate to a layer thickness of 0.05 $\mathrm{mm}$, and then a single bead was formed by scanning the laser in a single line using the optimal parameters. The surface of the bead sample was observed using SEM.

\section{Results}

\subsection{Densification of SLM samples}

The optimal laser scanning parameters for each Al-xSi aluminum alloy powder were studied with respect to the densification of the SLM sample. As an example of this optimization process, experiments with Al-10Si are shown in Figs. 5 and 6. Here, the 
densities of SLM samples fabricated with various laser powers and scanning velocity were investigated at a constant scan distance of $0.1 \mathrm{~mm}$ (Fig. 5). The density peaked at a given scanning velocity for each laser power. Next, the effect of scan distance for densification was evaluated (Fig. 6) using similar experiments in order to achieve a higher density. We varied the scan distance under two or three combinations of laser power and scanning velocity selected from Fig. 5 (in the case of Al-10Si, laser power/ scanning velocity of $250 \mathrm{~W} / 1800 \mathrm{~mm} / \mathrm{s}$ and $300 \mathrm{~W} / 2000 \mathrm{~mm} / \mathrm{s}$ were used). Once again, the relative density peaked at a given scan distance for each combination of laser power and scanning velocity. From these results, we chose the optimal laser scanning parameters for SLM processing based on the maximum relative density of the samples. Similar experiments were conducted for the other Al-xSi powders, and the optimal laser scanning parameters for each Al-xSi SLM sample were obtained. These optimal laser scanning parameters are shown in Table 3. 


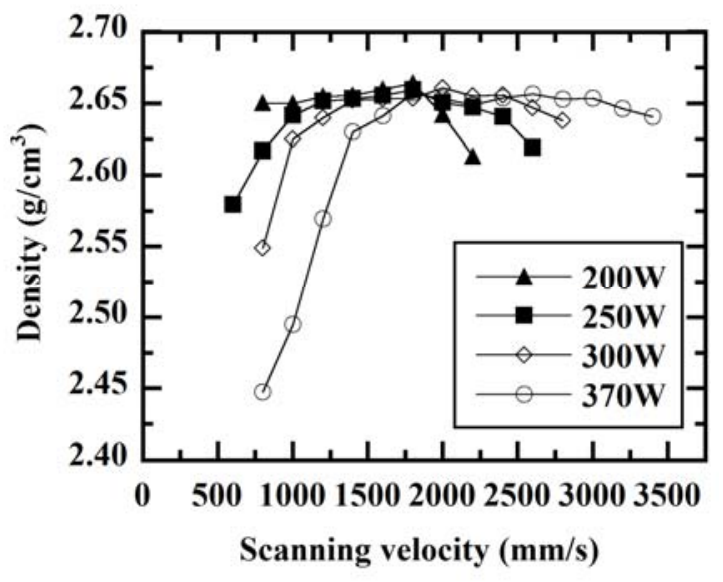

Fig. 5 Effect of scanning velocity and laser power on the density of Al-10Si SLM samples.

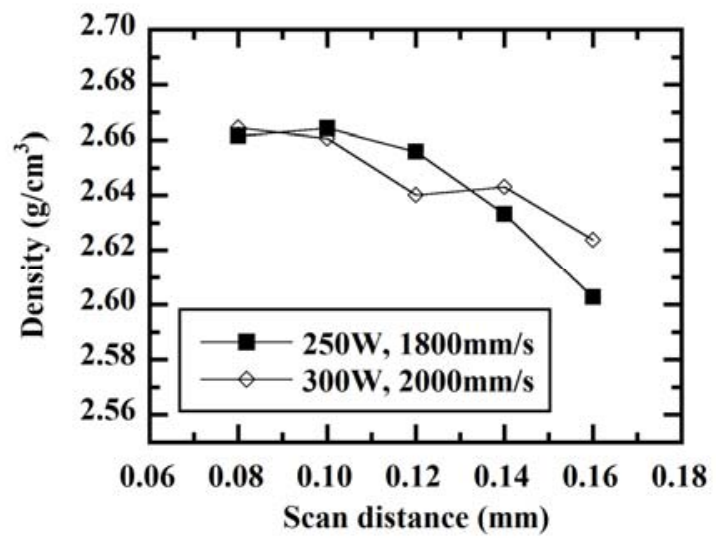

Fig. 6 Effect of scan distance on the density of Al-10Si SLM samples.

Table 3 Optimal laser scanning parameters to achieve the highest density for each Al-xSi powder.

\begin{tabular}{cccc}
\hline Sample & $\begin{array}{c}\text { Power } \\
\text { (W) }\end{array}$ & $\begin{array}{c}\text { Scanning velocity } \\
(\mathbf{m m} / \mathbf{s})\end{array}$ & $\begin{array}{c}\text { Scan distance } \\
(\mathbf{m m})\end{array}$ \\
\hline Al-0S1 & 370 & 1600 & 0.1 \\
Al-1S1 & 200 & 600 & 0.1 \\
Al-4S1 & 250 & 1200 & 0.08 \\
Al-7S1 & 250 & 1600 & 0.1 \\
Al-10S1 & 300 & 2000 & 0.08 \\
Al-12S1 & 250 & 1800 & 0.1 \\
Al-20S1 & 250 & 2000 & 0.08 \\
\hline
\end{tabular}


Fig. 7 shows optical microscopic images of XY-planes of Al-xSi SLM samples fabricated using the optimal laser scanning parameters. The (c)Al-4Si, (d)Al-7Si, (e)Al-10Si, and (f)Al-12Si samples showed no defects; whereas the (a)Al-0Si and (g)Al-20Si samples contained a few tiny spherical defects (less than $10 \mu \mathrm{m}$ ). The spherical defects are considered to be gas pores based on their morphological features. Kimura et al. $[6,11]$ investigated the composition of the gas in similar spherical pores of AlSi7Mg0.3 and AlSi10Mg aluminum SLM samples, and identified argon from the atmosphere of the building chamber, along with degassed hydrogen that was dissolved in the powder. Based on this, the tiny spherical pores found in the present study would be attributed to argon and hydrogen gas. Meanwhile, the (b)Al-1Si SLM sample contained many microcracks over the entire cross-sections, the cause of which is discussed in section 4.2 .
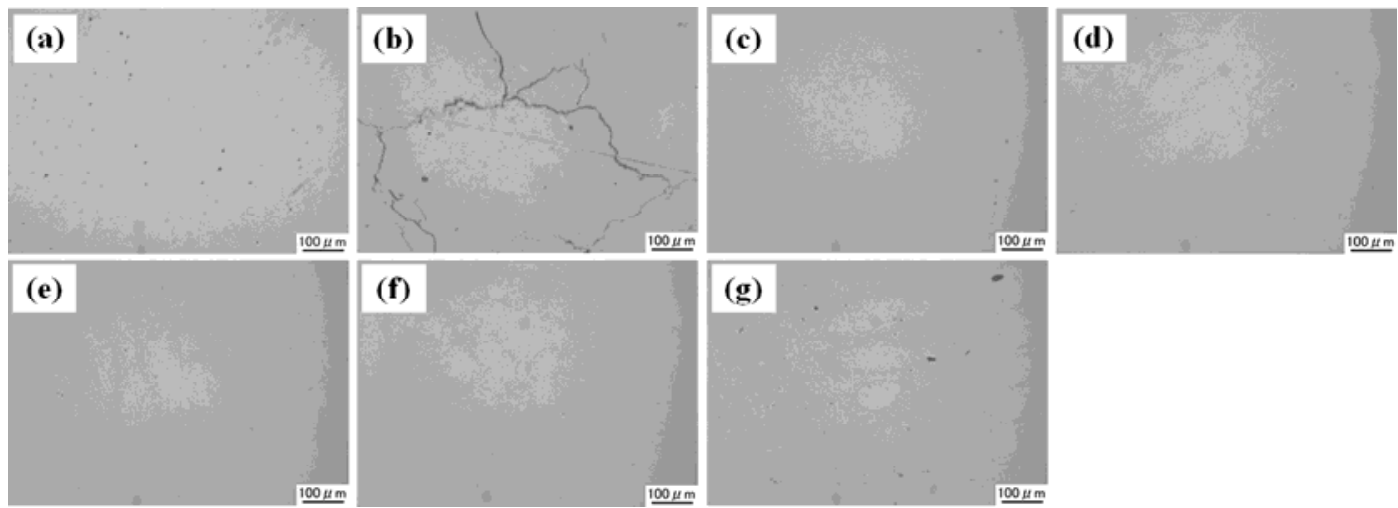

Fig. 7 Optical microscopic images showing XY-planes of Al-xSi SLM samples fabricated using the optimal laser scanning parameters. (a)Al-0Si, (b)Al-1Si, (c)Al-4Si, (d)Al-7Si, (e)Al-10Si, (f)Al-12Si, and (g)Al-20Si. 
Fig. 8 shows the relative density of each Al-xSi SLM sample fabricated using the optimal laser scanning parameters as a function of silicon content, as derived through thresholding analysis of five optical images (including Fig. 7). The relative density of the Al-0Si and Al-20Si SLM samples, both of which contained a small volume of tiny gas pores, was approximately $99.7 \%$. The relative density of the Al-1Si SLM sample was lower (about 97\%) due to the microcracks observed in Fig. 6(b). The Al-4 12Si SLM samples all had relative densities of almost $100 \%$.

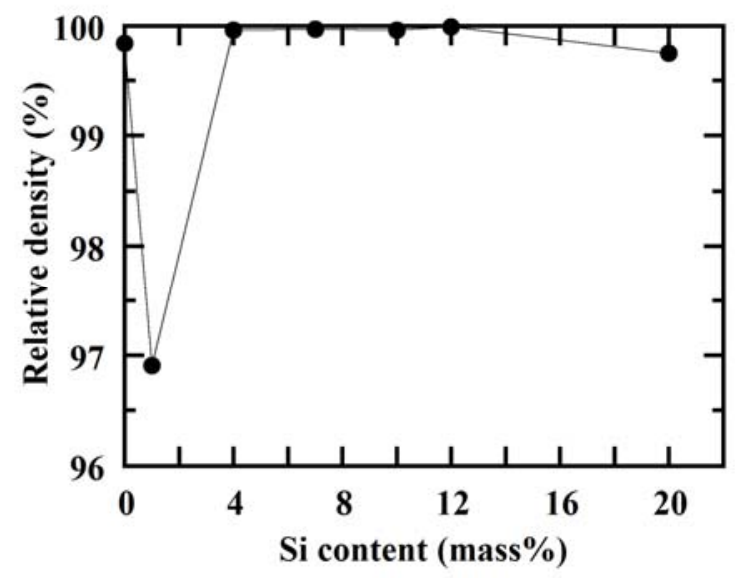

Fig. 8 Relative density derived through thresholding analysis of optical images of Al-xSi SLM samples fabricated using the optimal laser scanning parameters.

\subsection{Microstructures}

The optical microscopic images in Fig. 9 shows the metal structures of etched 
XY-planes (-1) and Z-planes (-2) of Al-xSi SLM samples fabricated using the optimal laser scanning parameters. All SLM samples had oval metal structures in the XY-planes, whereas semi-circular ones in the Z-planes. The width of these structures was about 0.1 $\mathrm{mm}$, which was the same size as the spot diameter of the laser. Judging from the size and shape of these metal structures, they are likely traces of the laser surrounded by solidification boundaries. Microcracks observed in the Al-1Si SLM sample were in a tortoise shell form in the XY-plane (b-1) and linked along the stacking direction across the solidification boundary in the Z-plane (b-2). The contrast of the Al-20Si SLM sample $(\mathrm{g}-1,-2)$ is clearly different from the Al-0 12Si samples. This is because the primary crystallization phase changed from aluminum to silicon (i.e. from a hypo-eutectic to hyper-eutectic composition) with increasing silicon content above the eutectic composition of the Al-Si binary alloy (12.6\% Si, as shown in Fig. 1). 

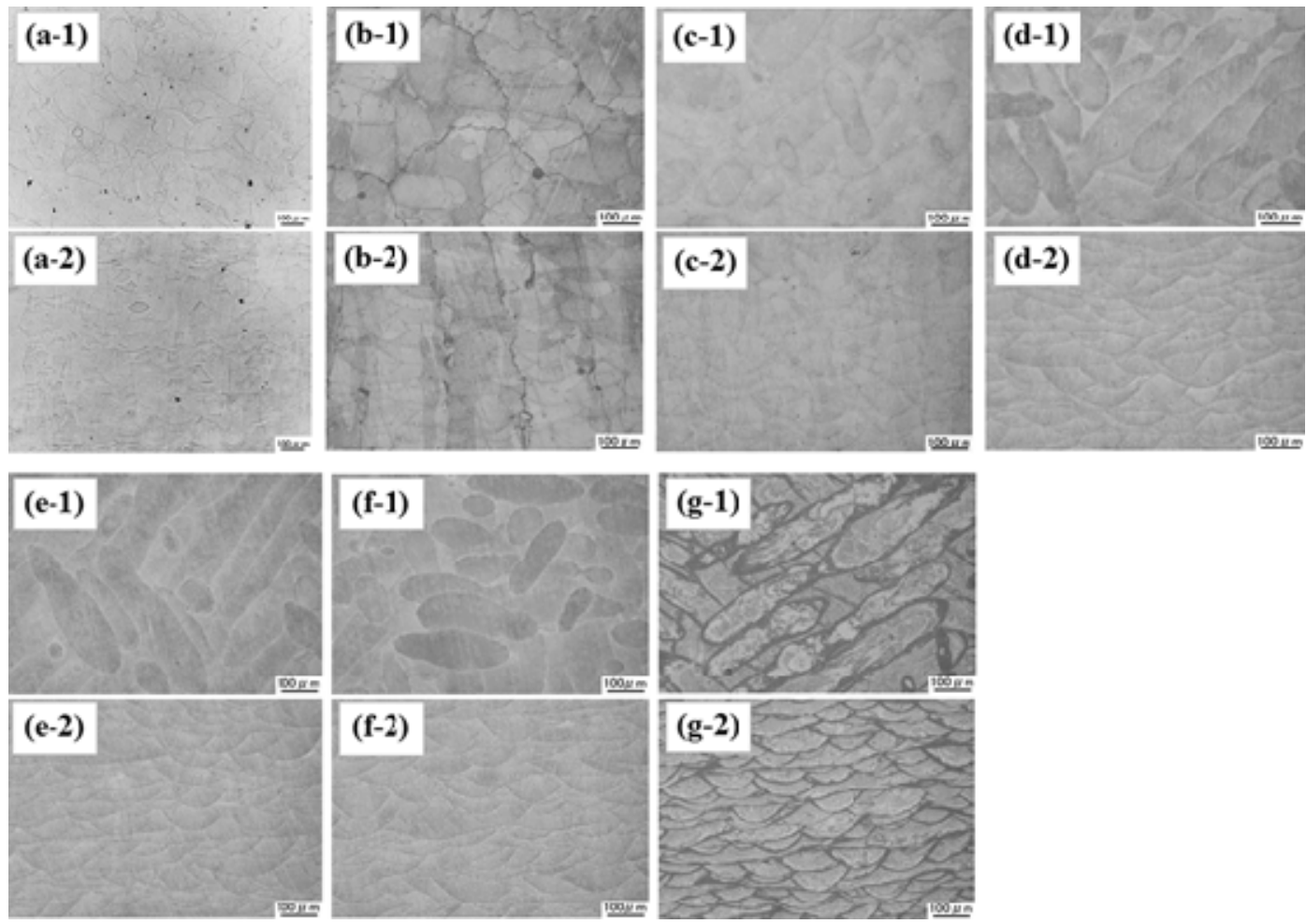

Fig. 9 Optical microscopic images of etched XY-planes (-1) and Z-planes (-2) of etched Al-xSi SLM samples fabricated using the optimal laser scanning parameters. (a) Al-0Si, (b) Al-1Si, (c) Al-4Si, (d) Al-7Si, (e) Al-10Si, (f) Al-12Si, and (g) Al-20Si.

Fig. 10 shows higher magnification SEM images of the etched XY-planes (-1) and Z-planes (-2) at the center of a laser trace of each Al-xSi SLM sample. The microstructures changed significantly with increasing silicon content of the Al-xSi powders. The Al-0Si SLM sample (a-1, 2) had a finely dispersed granular microstructures $(\sim 0.3 \mu \mathrm{m})$ due to rapid solidification by the laser irradiation. These granular microstructures are considered to be aluminum, silicon, and/or iron oxides, as reported by Kimura et al. [12]. Anisotropy of the microstructures (a difference between 
the XY-plane (a-1) and Z-plane (a-2)) was not observed in the Al-0Si SLM sample. The Al-1Si SLM sample $(b-1,2)$ exhibited granular microstructures considered to be oxides similar to Al-0Si with partially linked crystalized phases of Si. Microcracks of less than $1 \mu \mathrm{m}$ in width were clearly observed in both the XY-planes (b-1) and Z-planes (b-2). The microstructure of the Al-4Si SLM sample was considerably fine dendritic cells (approximately $0.5 \mu \mathrm{m}$ in cell size) in the XY-plane (c-1), in which the cell boundaries were divided in some places. The microstructures of the Al-4Si SLM sample in the Z-plane (c-2) were of elongated cells parallel to the stacking direction (i.e., the thermal flow direction). The microstructures of the Al-7 12Si SLM samples (d f-1, 2) were similar fine dendritic cells with continuous cell boundaries. The microstructures of the Al-7 12Si samples in the Z-planes were also elongated cells along the stacking direction. These cells are primary crystalized $\alpha$-Al phases with super-saturating of silicon, and the fine cell boundaries are crystalized phases of silicon. This fine cellular microstructural morphology is characteristic of SLM materials, being generated by the high solidification rate by laser irradiation. Tang et al. [13] and Li et al. [14] estimated cooling rates of AlSi10Mg SLM samples to be $2 \times 10^{6} \mathrm{~K} / \mathrm{s}$ and $1.25-6.17 \times 10^{6} \mathrm{~K} / \mathrm{s}$ respectively. The cooling rate in this study was also much higher than that of casting materials (permanent mold casting: $\sim 10 \mathrm{~K} / \mathrm{s}$, high-pressure die casting: $\sim 10^{3} \mathrm{~K} / \mathrm{s}$ ), and 
hence extremely fine microstructures were formed. The microstructures of the Al-20Si

SLM samples $(g-1,2)$ displayed characteristic petaloid structures which were remarkably different from those of the other samples with lower silicon levels, and are considered to be primary crystalized $\beta$-Si phases. No anisotropy was observed in this microstructures (i.e. there was no appreciable difference between the XY-plane (g-1) and Z-plane (g-2)).
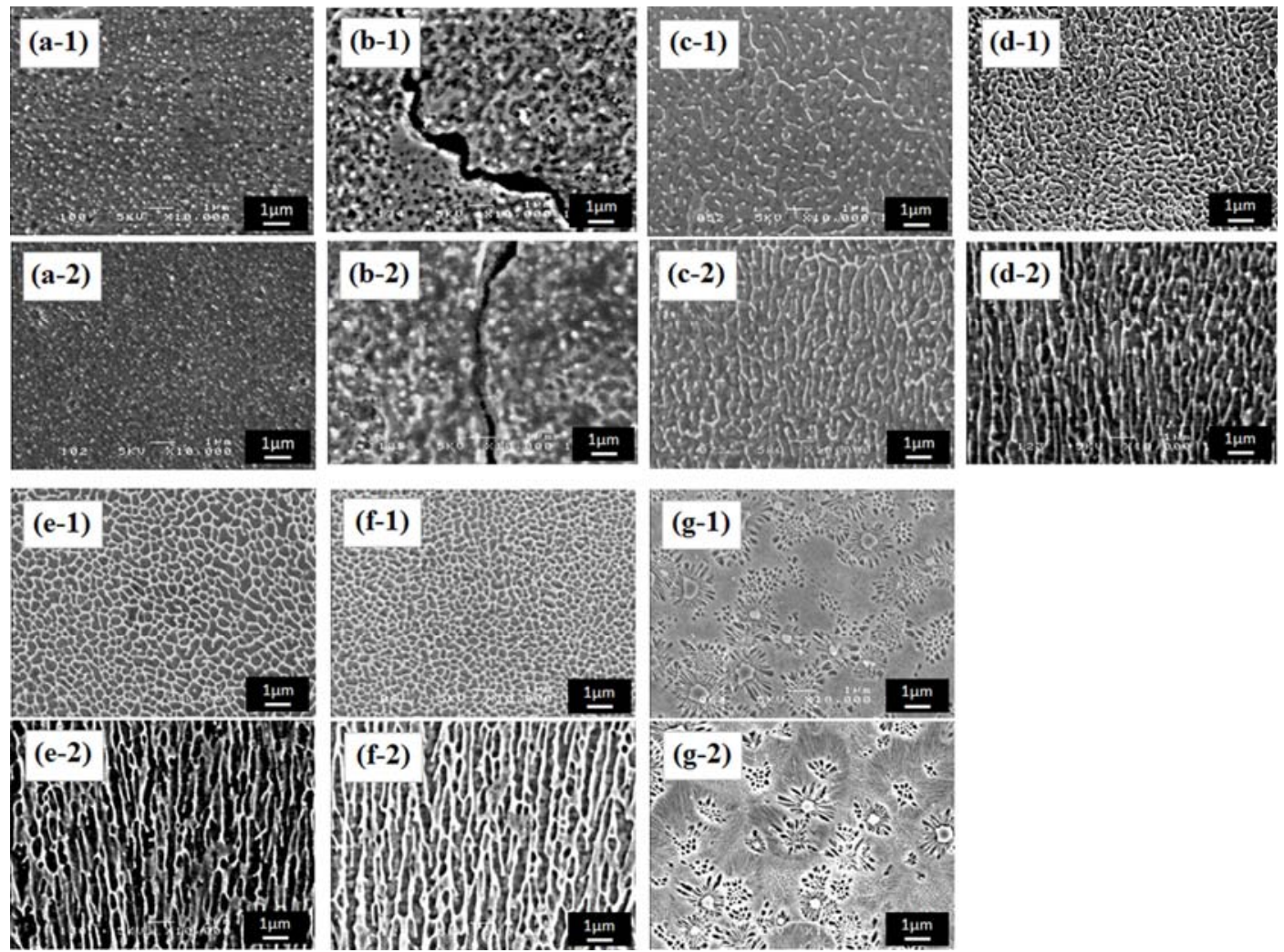

Fig. 10 SEM images of etched XY-plane (-1) and Z-plane (-2) of Al-xSi SLM samples fabricated using the optimal laser scanning parameters. (a) Al-0Si, (b) Al-1Si, (c) Al-4Si, (d) Al-7Si, (e) Al-10Si, (f) Al-12Si, and (g) Al-20Si. 


\subsection{Mechanical and thermal properties}

Fig. 11 shows the ultimate tensile strength and $0.2 \%$ proof stress as a function of silicon content for the Al-xSi SLM samples fabricated using the optimal laser scanning parameters. The Al-0Si SLM samples both in the $0^{\circ}$ and $90^{\circ}$ directions showed tensile strengths of about $110 \mathrm{MPa}$. The Al-1Si SLM sample in the $0^{\circ}$ direction showed a similar tensile strength of $110 \mathrm{MPa}$, while that in the $90^{\circ}$ direction was extremely low (about $25 \mathrm{MPa}$ ). Microcracks were generated along the stacking direction, as shown in Fig. 9(b-2), and the $90^{\circ}$ tensile SLM samples were fabricated perpendicular to the stacking direction. The cracks in the $90^{\circ}$ tensile samples therefore existed perpendicular to the tensile direction, which would lead to a decrease in the tensile strength. As the silicon content increased above 4 mass $\%$, the tensile strengths both in the $0^{\circ}$ and $90^{\circ}$ samples monotonically increased; the value for the Al-20Si SLM sample reached more than $550 \mathrm{MPa}$. Differences in the tensile strengths between the $0^{\circ}$ and $90^{\circ}$ samples were not observed for silicon content above 4 mass $\%$ (Al-4 20Si). The proof stress values had a similar trend to the tensile strength. The proof stress of the Al-0Si SLM sample was about $90 \mathrm{MPa}$ both in the $0^{\circ}$ and $90^{\circ}$ directions. The proof stress of the Al-1Si SLM sample in the $0^{\circ}$ direction was about $80 \mathrm{MPa}$, whereas that in the $90^{\circ}$ direction was 25 MPa because of the microcracks mentioned above. The proof stress increased steadily 
with increasing silicon content above 4 mass $\%$ to a final value of $420-475 \mathrm{MPa}$ for the Al-20Si SLM sample. The proof stress of the $0^{\circ}$ samples for silicon content above 4 mass $\%$ were less than those of the $90^{\circ}$ samples.

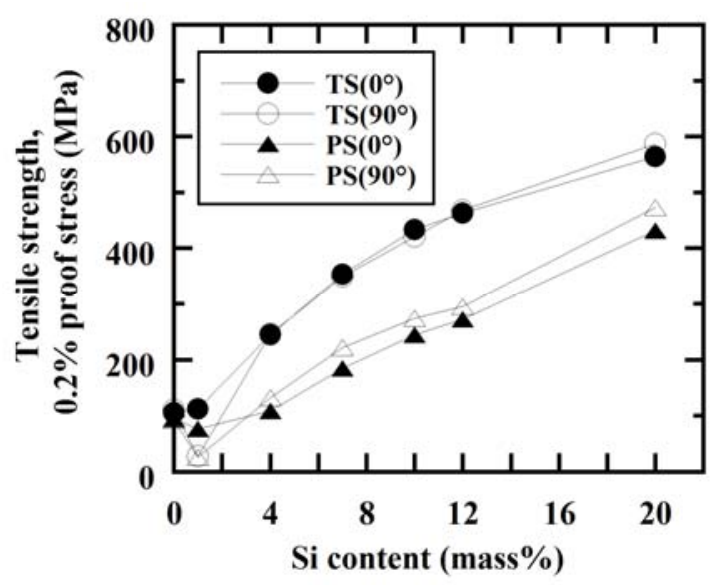

Fig. 11 Tensile strength and proof stress of Al-xSi SLM samples fabricated using the optimal laser scanning parameters.

Fig. 12 shows the breaking elongation as a function of silicon content for the Al-xSi SLM samples fabricated using the optimal laser scanning parameters. The elongation of the Al-0Si sample was about $30 \%$ in both the $0^{\circ}$ and $90^{\circ}$ samples, which is equivalent value to the wrought material. The breaking elongation of the Al-1Si SLM sample decreased significantly to $10 \%$ in the $0^{\circ}$ sample and to $1 \%$ in the $90^{\circ}$ sample. This low elongation was also due to the microcracks observed in Fig. 7(b). The breaking elongation decreased with increasing silicon content above 4 mass $\%$ in contrast to the 
tensile strength and proof stress. The elongation of $20 \%$ for the Al-4Si SLM sample dropped to $2 \sim 4 \%$ for the Al-20Si SLM sample. The elongation values of the $0^{\circ}$ samples for silicon content above 4 mass $\%$ were less than those of the $90^{\circ}$ samples.

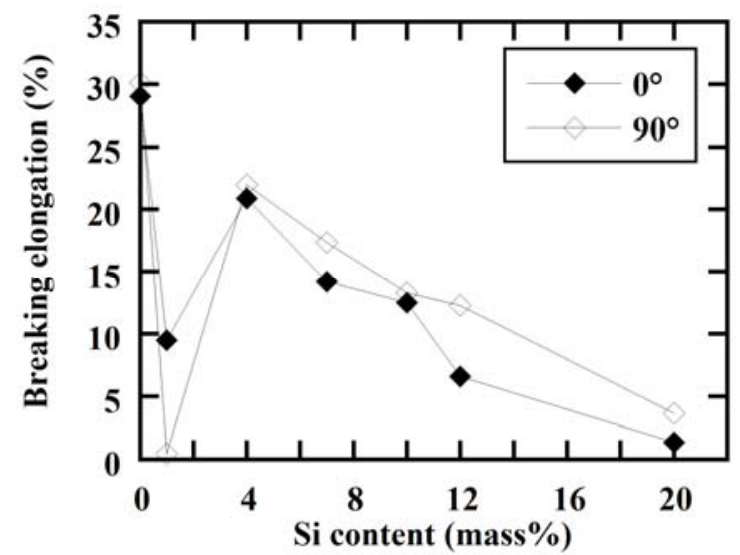

Fig. 12 Breaking elongation of Al-xSi SLM samples fabricated using the optimal laser scanning parameters.

Fig. 13 shows the thermal conductivity as a function of silicon content for the Al-xSi SLM samples fabricated using the optimal laser scanning parameters. The thermal conductivity showed a similar tendency to the breaking elongation. The thermal conductivity of Al-0Si showed the highest value (about $200 \mathrm{~W} / \mathrm{m} \cdot \mathrm{K}$ ). This value is a little smaller than that of wrought material of the same composition (A1060 plate, about $230 \mathrm{~W} / \mathrm{m} \cdot \mathrm{K})$. The thermal conductivity of the Al-1Si SLM sample in the $0^{\circ}$ sample was $180 \mathrm{~W} / \mathrm{m} \cdot \mathrm{K}$ and that in the $90^{\circ}$ sample was $130 \mathrm{~W} / \mathrm{m} \cdot \mathrm{K}$. At silicon content above 4 
mass $\%$, the thermal conductivity decreased gradually with increasing silicon content. The thermal conductivity of about $160 \mathrm{~W} / \mathrm{m} \cdot \mathrm{K}$ for the Al-4Si SLM sample decreased to about $105 \mathrm{~W} / \mathrm{m} \cdot \mathrm{K}$ for the Al-20Si SLM sample. No anisotropy of the thermal conductivity between the $0^{\circ}$ and $90^{\circ}$ samples was observed in the Al-xSi SLM samples except for Al-1Si.

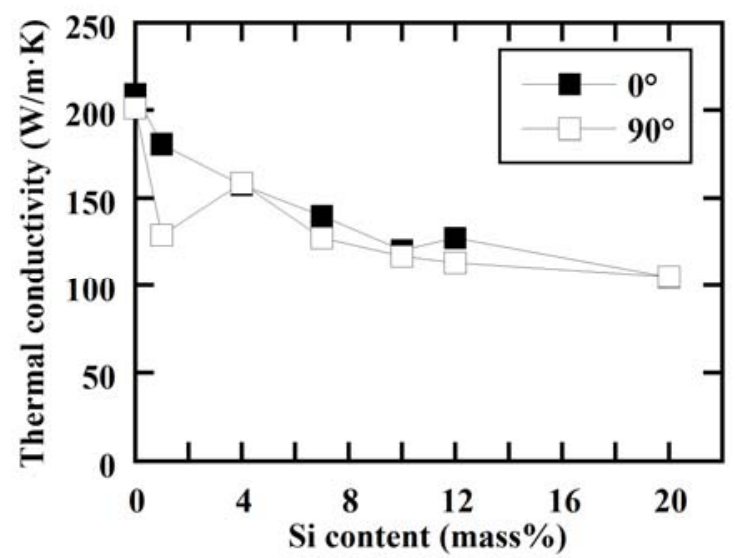

Fig. 13 Thermal conductivity of Al-xSi SLM samples fabricated using the optimal laser scanning parameters.

\section{Discussion}

\subsection{Densification mechanism}

It is well known that densification in SLM materials is dependent on the input energy density $\boldsymbol{E}_{\boldsymbol{d}}\left(\mathrm{J} / \mathrm{mm}^{3}\right)$, as expressed below as a function of the laser power $\boldsymbol{P}(\mathrm{W})$, scanning velocity $\boldsymbol{v}(\mathrm{mm} / \mathrm{s})$, scan distance $\boldsymbol{d}(\mathrm{mm})$, and layer thickness $\boldsymbol{t}(\mathrm{mm})$. 


$$
E_{d}=P /(v \cdot d \cdot t)
$$

$\mathrm{Gu}$ et al. [15] showed that the densification of SLM samples with 17-4PH stainless steel powder could be described using the input energy density. Nakamoto et al. [16] demonstrated that the relative density of SLM samples with low carbon steel powder was correlated to the input energy density. Kimura et al. $[6,11]$ showed that the relative density of AlSi7Mg0.3 and AlSi10Mg aluminum SLM samples could generally be ordered by the input energy density.

Fig. 14 shows the input energy density required to obtain SLM samples with the highest density for each Al-xSi powder as a function of silicon content, as calculated from the optimal laser scanning parameters shown in Table 3. Data for the Al-1Si SLM sample was not included because of its low relative density (less than 97\%), which was the result of microcracks. The input energy density required for densification of Al-0Si SLM sample was approximately $80 \mathrm{~J} / \mathrm{mm}^{3}$, and that of Al-4Si SLM sample was nearly $90 \mathrm{~J} / \mathrm{mm}^{3}$. The input energy density for densification decreased to $50 \sim 60 \mathrm{~J} / \mathrm{mm}^{3}$ above silicon content of 7 mass $\%$ (Al-7 20Si). 


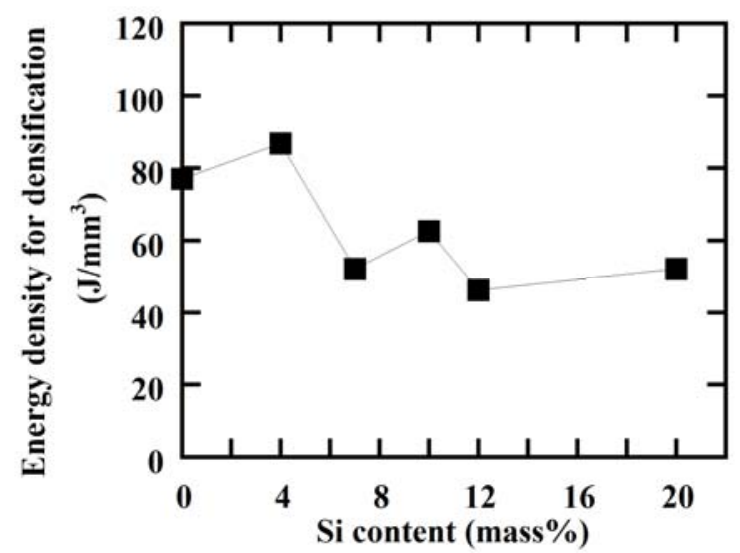

Fig. 14 Input energy density for densification of Al-xSi SLM samples.

This energy density behavior is considered to be related to the flowability of the molten metals in each Al-xSi alloy. Kummerle et al. [17] studied the flowability of the Al-Si casting alloys as a function of silicon content using a swirl mold. These results showed that the flowability of pure aluminum was relatively high and decreased with increasing silicon content until about 4 mass $\%$. At silicon content above 4 mass $\%$, the flowability increased up to a silicon content of 20 mass $\%$. Namely, the flowability of Al-Si alloys in casting showed a minimum value at a silicon content of around 4 mass $\%$. Isobe et al. [18] and Nishi et al. [19] also measured the flowability of Al-Si casting alloys using a vacuum suction type flowability method (the MIT method, introduced by Nisse et al. [20]). They also found that the flowability of Al-Si casting alloys showed a minimum value at silicon content of around 4 5 mass $\%$. 
Based on these studies, the change of the input energy density for densification in Al-xSi SLM samples (Fig. 14) can be explained as follows. The alloys with high flowability (Al-7 20Si) can allow the molten metal to spread easily over the solidified surface when laser melting the next layer, even with a low input energy density. Therefore, the Al-7 20Si SLM samples did not need a high input energy density to densify. On the other hand, the alloys with low flowability (Al-0 4Si) needed a high input energy density to increase the temperature and improve the flowability of the molten metal for spreading over the solidified surface. Accordingly, it is considered that the higher the flowability of the molten Al-xSi alloys, the lower the input energy density required to densify the SLM samples.

\subsection{Crack generation in $\mathrm{Al}-1 \mathrm{Si}$ SLM sample}

In the case of Al-1Si alloy, although a high input energy density was applied for densification, the achieved relative density of the Al-1Si SLM sample was less than $97 \%$ due to the microcracks observed. Additionally, the microcracks were generated regardless of the scanning parameters. As a result, the input energy density of the optimum laser scanning parameters for the Al-1Si SLM sample was relatively high. This suggests that the generation of the microcracks observed only in the Al-1Si SLM 
sample is not related to the input energy density. Accordingly, the microcracks are considered as solidification cracks. It is well known that high residual stresses are generated in SLM samples due to local shrinkage caused by local heating (thermal gradient) from the laser irradiation. Buchbinder et al. [21] demonstrated that an AlSi10Mg aluminum SLM material contained thermally induced residual stresses, which can lead to distortion of fabricated components. The thermally induced tensile stresses by local shrinkages can be a main factor of solidification cracks in the Al-1Si SLM sample. Namely, the solidification cracks in the SLM samples were considered to be generated when the thermally induced tensile stresses and/or strain exceeded the tensile strength and/or elongation of the molten metal (in the solid-liquid coexisting state) of the SLM alloys during solidification.

Fig. 15 shows a single bead formed using SLM with the Al-1Si powder. A few cracks, as shown by arrows, were observed from the center to the edge of the bead. This suggests that the cracks were generated not in the bulk state, but in the single bead, and that the Al-1Si alloy was extremely brittle during the SLM process. Furthermore, these cracks should increase due to the formation of planes by aggregation of the beads through sequential laser scanning. Fig. 16 shows an IPF (inverse pole figure) map of the Z-plane of the Al-1Si SLM sample analyzed by EBSD. It was found that the cracks 
were generated along the grain boundaries and the crystal grains on either side of the cracks had different crystallographic directions. This means that the cracks were formed before or during crystal growth (in the solid-liquid coexisting state). Fig. 17 shows the fracture surface of $0^{\circ}$ and $90^{\circ}$ tensile SLM samples of the Al-1Si alloy. Solidified equiaxed grain microstructures with a size of $\sim 200 \mu \mathrm{m}$ were clearly observed in the $0^{\circ}$ sample. Elongated grain microstructures along the stacking direction were found in the $90^{\circ}$ sample. These grain microstructures of the fracture surfaces are consistent with those found in the IPF map (Fig. 16). This also suggests that the cracks were occurred before the solidification was complete. These results (Figs. 15 17) support the hypothesis that the cracks found in the Al-1Si SLM sample were solidification cracks.

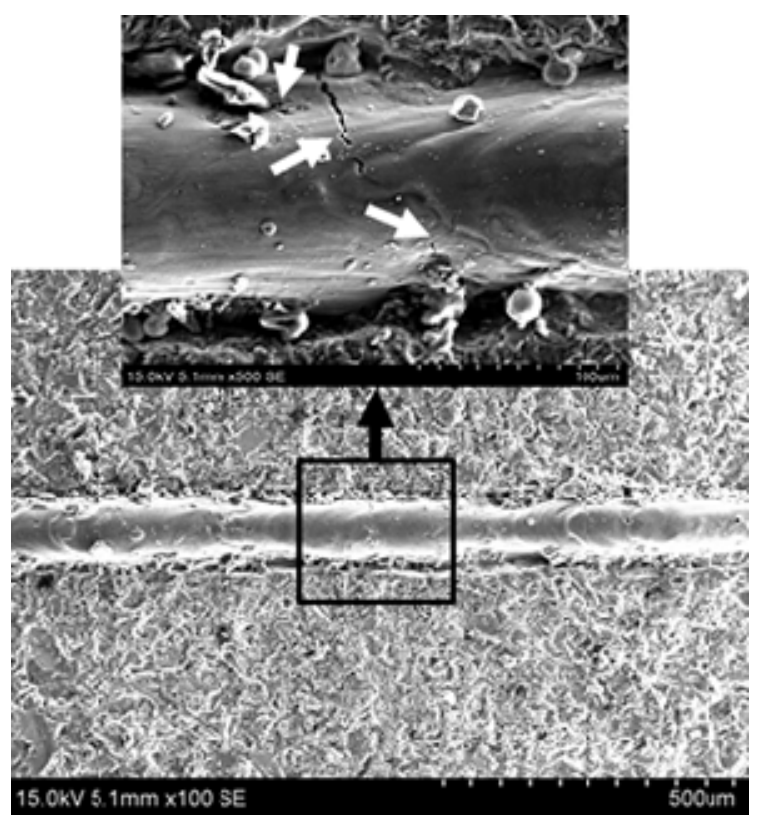

Fig. 15 SEM images of a single bead fabricated by SLM with Al-1Si powder. 


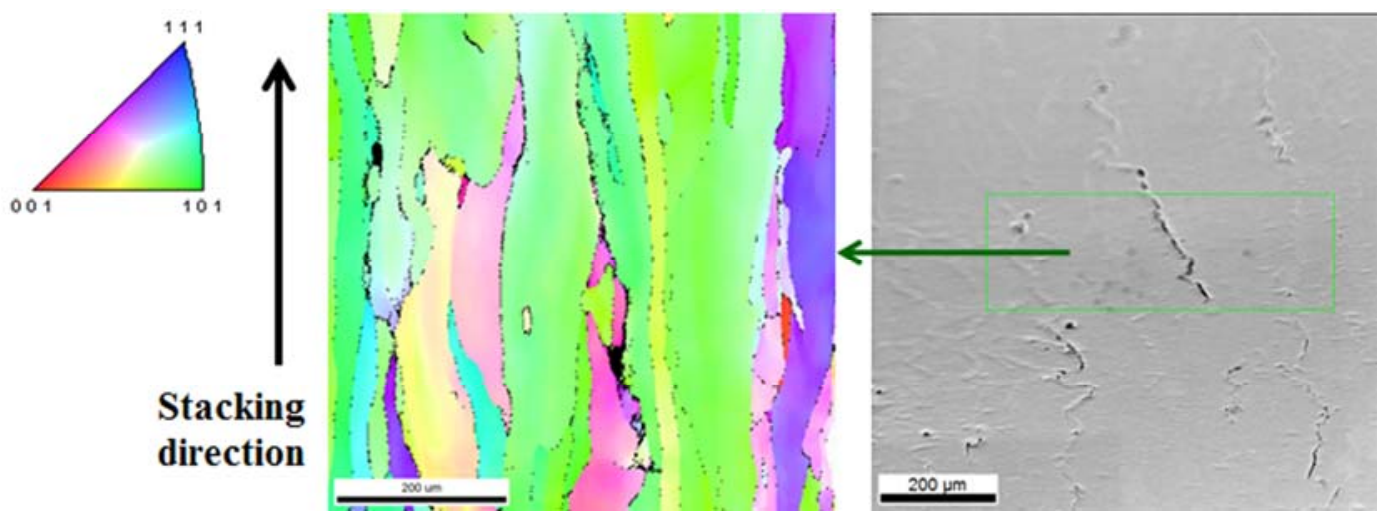

Fig. 16 IPF map of a Z-plane of the Al-1Si SLM sample analyzed by EBSD.
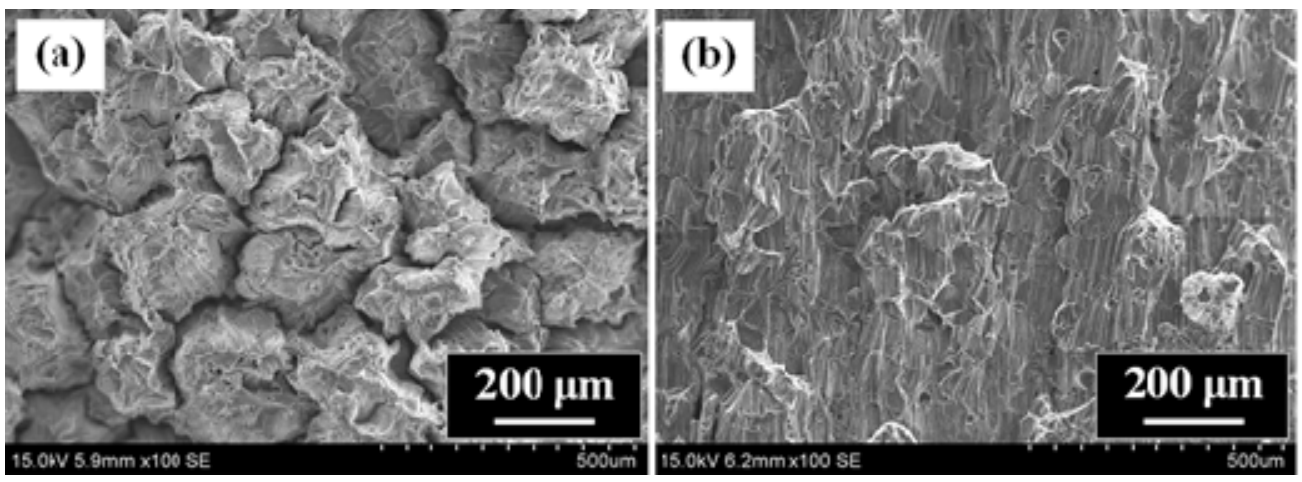

Fig. 17 SEM images of fracture surfaces of (a) $0^{\circ}$ and (b) $90^{\circ}$ tensile SLM samples of the Al-1Si.

The solidification cracks were studied also in Al-Si casting materials. Isobe et al.

[22] investigated the length of solidification cracks in Al-Si alloys using permanent mold casting with a ring mold. According to their study, Al-Si casting alloys with a silicon content of around 1.0 mass $\%$ showed the longest and highest frequency of solidification cracks. They explained that the Al-1Si casting material in the solid-liquid 
coexisting state was relatively brittle because the dendrite solid phases were locked together (dendrite interlocking state), and additionally healing of the cracks by liquid infiltration was not effective. Singer et al. [23] and Davies [24] also presented similar results, i.e., aluminum alloys with silicon content of $0.5-1.0$ mass $\%$ showed a high generation of solidification cracks in Al-Si casting alloys. This phenomenon can also apply to the Al-Si SLM samples. Namely, it is considered that the Al-1Si SLM sample in the solid-liquid coexisting state was brittle and healing of the cracks by liquid infiltration could not occur when solidifying. Therefore, the cracks were easily formed in the Al-1Si SLM sample due to the thermally induced tensile stresses caused by the laser irradiation, as mentioned above.

Hence, it became clear that the SLM sample of Al-1Si had a high sensitivity to solidification cracks. Therefore, a silicon content of around 1 mass $\%$, also in the case of aluminum SLM materials, should be avoided to prevent the solidification cracks. Alternatively, in order to prevent cracking it could be effective to reduce the thermally induced tensile stresses to the absolute minimum (e.g., by means of in situ high temperature heating during the SLM process for reducing the thermal gradient).

\subsection{Relationship between microstructures and properties}


From Figs. 11 13, it was observed that the ultimate tensile strength and proof stress increased significantly with increasing silicon content, whereas the elongation and thermal conductivity decreased. Namely, the strength had a trade-off relationship with the breaking elongation and thermal conductivity. This tendency can be explained with respect to the microstructures shown in Figs. 9 and 10.

It is obvious that the poor mechanical and thermal properties of the Al-1Si SLM sample were due to the microcracks (solidification cracks) discussed in section 4.2. In the Al-4 12Si SLM samples, it was confirmed that the area fraction of the silicon crystalized phases (cell boundaries) increased with increasing silicon content, as observed in Fig. 10. Such crystalized phases of silicon can be obstacles to the movement of dislocations. Therefore, the increase in the tensile strength and $0.2 \%$ proof stress of the SLM samples with increasing silicon content could be attributed to composite reinforcement by the increased proportion of the silicon crystalized secondary phases. Moreover, the increase in the solid solubility of silicon in the aluminum matrix with increasing silicon content may also have strengthened the SLM material. On the other hand, the crystalized phases caused discontinuities in the aluminum matrix. This led to a decrease in the breaking elongation because such discontinuities could be crack initiation points. Additionally, the crystalized phases can 
act as scattering sites for conduction electrons. The decrease in the thermal conductivity was considered to arise from the increase in the thermal resistivity by scattering of conduction electrons with increasing the crystalized phases. In the Al-20Si SLM sample, the primary crystalized phase was silicon, that is well known to be very hard; therefore, the strength properties increased and the elongation decreased. In addition, the thermal conductivity decreased with increasing content of silicon solute behaving as scattering sites for conduction electrons.

The anisotropy of the proof stress was attributed to the anisotropy of the microstructures shown in Fig. 10. The microstructure of the aluminum SLM samples was dendritic cells elongated along the stacking direction. The crystalized phases of silicon were observed more frequently in the $90^{\circ}$ direction to the stacking direction compared to $0^{\circ}$ direction. This was thought to contribute to the higher proof stress of the $90^{\circ}$ tensile samples as a result of pile-ups of dislocations at the crystalized phases. The anisotropy of the breaking elongation was probably related to the solidification boundaries observed in Fig. 9. The solidification boundaries of the SLM samples arrayed in vertical layers to the stacking direction. Additionally, the solidification boundaries consisted of coarsened cells and precipitated silicon zones (HAZ, heat affected zones), as discussed by Aboukhair et al. [25] and Kimura et al. [6] in relation to 
aluminum SLM samples prepared from AlSi10Mg and AlSi7Mg0.3 alloys, respectively. This caused the $0^{\circ}$ tensile samples to break easily in layers vertical to the stacking direction along the solidification boundaries, and so the breaking elongation of the $90^{\circ}$ tensile samples was much higher.

\section{Conclusions}

The effect of silicon content on the densification of Al-xSi alloys fabricated using selective laser melting was systematically studied. The microstructure of the Al-xSi SLM samples were also evaluated along with their mechanical and thermal properties. We reached the following conclusions from analysis of the densification mechanism and relationship between the microstructures and the mechanical and thermal properties of the Al-xSi SLM samples.

(1) Full density (relative density of almost 100\%) was achieved in Al-4 12Si SLM samples by optimizing the laser scanning parameters. Almost fully dense SLM samples (relative density of more than 99.5\%) were obtained for Al-0Si (pure aluminum) and Al-20Si SLM samples. The densification 
mechanism was explained by the flowability of the molten metals for each Al-xSi alloy.

(2) Microcracks over the entire cross-section along the stacking direction were generated in the Al-1Si SLM sample. The cracks were solidification cracks occurred due to the thermally induced tensile stresses. A silicon content of around 1 mass $\%$ in the Al-Si SLM samples should be avoided to prevent failures of SLM samples because of a high sensitivity for solidification cracks.

(3) As the silicon content of the Al-xSi SLM samples increased, the ultimate tensile strength and proof stress of the SLM samples increased, whereas the elongation and thermal conductivity decreased. The changes in the mechanical and thermal properties were due to the increase of the crystalized phases and solid solubility of silicon in the aluminum matrix.

\section{Acknowledgements}

This work was partially supported by the Council for Science, Technology and Innovation (CSTI), Cross-Ministerial Strategic Innovation Promotion Program (SIP), Innovative design/manufacturing technologies (Establishment and Validation of the 
Base for 3D Design \& Additive Manufacturing Standing on the Concepts of "Anisotropy" \& "Customization") from the New Energy and Industrial Technology Development Organization (NEDO), Japan.

This work was also partially supported by the Matching Planner Program from Japan Science and Technology Agency, JST.

\section{References}

[1] I. Gibson, D. W. Rosen, B. Stucker, Powder Bed Fusion Processes, Additive manufacturing technologies, Springer, New York, 2010, pp. 103-142.

[2] W. M. Steen, J. Mazumder, Rapid Prototyping and Low-volume Manufacture, Laser Material Processing 4th Edition, Springer, New York, 2010, pp. 349-369.

[3] W. M. Steen, J. Mazumder, Laser Surface Melting, Laser Material Processing 4th Edition, Springer, New York, 2010, pp. 309-318.

[4] T. Nakamoto, N. Shirakawa, Y. Miyata, T. Sone, H. Inui, Selective laser sintering of high carbon steel powders studied as a function of carbon content, J. Mater. Process. Technol. 209 (2009) 5653-5660.

[5] K. Kempen, L. Thijs, V. J. Humbeeck, J. P. Kruth, Mechanical Properties of AlSi10Mg Produced by Selective Laser Melting, Physics Procedia. 39 (2012) 
439-446.

[6] T. Kimura, T. Nakamoto, Microstructures and Mechanical Properties of A356 (AlSi7Mg0.3) aluminum alloy fabricated by selective laser melting, Mater. Des. 89 (2016) 1294-1301.

[7] K. G. Prashanth, S. Scudino, H. J. Klauss, K. B. Surreddi, L. Lober, Z. Wang, A. K. Chaubey, U. Kuhn, J. Eckert, Microstructure and mechanical properties of Al-12Si produced by selective laser melting: Effect of heat treatment, Mater. Sci. Eng. A 590 (2014) 153-160.

[8] E. O. Olakanmi, Selective laser sintering/melting (SLS/SLM) of pure Al, Al-Mg. and Al-Si powders: Effect of processing conditions and powder properties, J. Mater. Process. Technol. 213 (2013) 1387-1405.

[9] S. Kitaoka, Castability of aluminum casting alloys, J. Jpn. Inst. Light Metals 41 (1991) 365-372.

[10] S. Kitaoka, C. Fujikura, A. Kamio, Aluminum-Silicon alloys, J. Jpn. Inst. Light Metals 38 (1988) 426-446.

[11] T. Kimura, T. Nakamoto, Microstructures and Mechanical Properties of A1-10\%Si-0.4\%Mg Fabricated by Selective Laser Melting, J. Jpn. Soc. Powder Powder Metallurgy 61 (2014) 531-537. 
[12] T. Kimura, T. Nakamoto, Thermal and mechanical properties of commercial-purity aluminum fabricated using selective laser melting, J. Jpn. Inst Light Metals 66 (2016) 167-173.

[13] M. Tang, P. C. Pistorius, S. Narra, J. L. Beuth, Rapid Solidification: Selective Laser Melting of AlSi10Mg, J. Metals 68 (2016) 960-966.

[14] Y. Li, D. Gu, Parametric analysis of thermal behavior during selective laser melting additive manufacturing of aluminum alloy powder, Mater. Des. 63 (2014) $856-867$.

[15] H. Gu, H. Gong, D. Pal, K. Rafi, T. Starr, B. Stucker, Influences of Energy Density on Porosity and Microstructure of Selective Laser Melted 17-4PH stainless Steel, Solid Freeform Fabrication Symposium Proceedings, Austin Texas, The University of Texas, USA, 2013, pp. 474-489.

[16] T. Nakamoto, N. Shirakawa, Y. Miyata, T. Sone, H. Inui, Selective Laser Sintering and Subsequent Gas Nitrocarburizing of Low Carbon Steel Powder, Int. J. Automation Technol. 2 (2008) 168-174.

[17] R. Kummerle, Giesseigenschaften im System Aluminium-Silizium, Z. Metall. $11(1957) 848-854$.

[18] T. Isobe, A. Kubota, S. Kitaoka, Castability of Aluminum Alloys, J. Jpn. 
Foudrymen's Soc. 47 (1975) 345-355.

[19] S. Nishi, T. Shinoda, Proceedings of the Conference of Japan Institute of Light Metals, Japan, 1972, pp. 111-112.

[20] J. E. Nisse, M. C. Flemings, H. F. Tayler, 1959. Application of theory in understanding fluidity of metals, AFS Trans. 67, 685-697.

[21] D. Buchbinder, W. Meiners, N. Pirch, K. Wissenbach, Investigation on reducing distortion by preheating during manufacture of aluminum components using selective laser melting, J. Laser Applications 26 (2014) 012004-1-10.

[22] T. Isobe, A. Kubota, S. Kitaoka, Influence of Semi-Solid Temperature Range and the Rate of Increase in Strength during the Solidification Process on the Hot Tearing of Cast Aluminum Alloys, J. Jpn. Foudrymen's Society 50 (1978) 425-427.

[23] A. R. E. Singer, P. H. Jennings, Hot-shortness of the aluminium-silicon alloys of commercial purity, J. Inst. Metals 73 (1946) 197-212.

[24] V. L. Davies, The influence of grain size on hot tearing, The British Foundryman April (1970) 93-101.

[25] N. T. Aboulkhair, N. M. Everitt, I. Ashcroft, C. Tuck, Reducing porosity in AlSi10Mg parts processed by selective laser melting, Addit. Manufact. 1-4 (2014) $77-86$. 


\section{Figure captions}

Fig. 1 Chemical composition of Al-xSi powders shown on a schematic phase diagram of the Al-Si system alloy.

Fig. 2 SEM image of Al-10Si powder, representing the morphology of all test powders.

Fig. 3 Sectional planes of SLM samples for microstructural observation.

Fig. 4 Directions of SLM samples for tensile tests and laser flash measurements at angles of $0^{\circ}$ and $90^{\circ}$ to the stacking direction.

Fig. 5 Effect of scanning velocity and laser power on the density of Al-0Si SLM samples.

Fig. 6 Effect of scan distance on the density of Al-0Si SLM samples.

Fig. 7 Optical microscopic images showing XY-planes of Al-xSi SLM samples fabricated using the optimal laser scanning parameters. (a) Al-0Si, (b) Al-1Si, (c) 
Al-4Si, (d) Al-7Si, (e) Al-10Si, (f) Al-12Si, and (g) Al-20Si.

Fig. 8 Relative density derived through thresholding analysis of optical images of Al-xSi SLM samples fabricated using the optimal laser scanning parameters.

Fig. 9 Optical microscopic images of etched XY-planes (-1) and Z-planes (-2) of etched Al-xSi SLM samples fabricated using the optimal laser scanning parameters. (a) Al-0Si, (b) Al-1Si, (c) Al-4Si, (d) Al-7Si, (e) Al-10Si, (f) Al-12Si, and (g) Al-20Si.

Fig. 10 SEM images of etched XY-plane (-1) and Z-plane (-2) of Al-xSi SLM samples fabricated using the optimal laser scanning parameters. (a) Al-0Si, (b) Al-1Si, (c) Al-4Si, (d) Al-7Si, (e) Al-10Si, (f) Al-12Si, and (g) Al-20Si.

Fig. 11 Tensile strength and $0.2 \%$ proof stress of Al-xSi SLM samples fabricated using the optimal laser scanning parameters.

Fig. 12 Breaking elongation of Al-xSi SLM samples fabricated using the optimal laser 
scanning parameters.

Fig. 13 Thermal conductivity of Al-xSi SLM samples fabricated using the optimal laser scanning parameters.

Fig. 14 Input energy density for densification of Al-xSi SLM samples.

Fig. 15 SEM images of a single bead fabricated by SLM with Al-1Si powder.

Fig. 16 IPF map of a Z-plane of the Al-1Si SLM sample analyzed by EBSD.

Fig. 17 SEM images of fracture surfaces of (a) $0^{\circ}$ and (b) $90^{\circ}$ tensile SLM samples of the Al-1Si. 


\section{Table captions}

Table 1 Average particle diameter and chemical composition (mass\%) of Al-xSi powders.

Table 2 Range of laser scanning parameters.

Table 3 Optimal laser scanning parameters to achieve the highest density for each Al-xSi powder. 